REVISTA DE DERECHO UNED, NÚM. 11, 2012

\title{
EN TORNO A UNA CONSTRUCCIÓN AUTÓNOMA DE LA HISTORIA DE LA CIENCIA JURÍDICA PROCESAL ESPAÑOLA QUE FORME PARTE DEL DERECHO PROCESAL
}

\author{
CONCERNING AN AUTONOMUS CONSTRUCTION OF THE \\ HISTORY OF THE JURIDICAL PROCEDURAL SPANISH \\ SCIENCE THAT FORMS A PART OF THE PROCEDURAL LAW
}

\author{
Juan Manuel Alonso Furelos \\ Profesor Titular de Derecho Procesal
}

Resumen: El Dr. D. Manuel Jesús Cachón Cadenas en la obra citada construye los cimientos de lo que podríamos denominar la Historia de la Ciencia Jurídica Procesal Española.

Toda la obra se refiere a aspectos de lo que podríamos denominar su parte especial pero a la vez, y es muy importante, de forma abstracta fija las pautas de una parte general.

A través de esas pautas trato de adentrarme en la posible e hipotética construcción autónoma de dicha parte general que formaría parte del derecho procesal.

Palabras clave: Historia. Ciencia. Jurídica. Procesal. Española.

Abstract: The Dr. D. Manuel Jesús Cachón Cadenas in the mentioned work constructs the foundations of what we might name the History of the Juridical Procedural Spanish Science.

The whole work refers to aspects of what we might determine his special part but simultaneously, and is very important, of abstract form it fixes the guidelines of a general part. 
Through these guidelines I try to delve into the possible and hypothetical autonomous construction of the above mentioned general part that would form a part of the procedural law.

Keywords: History. Science. Juridical. Legal. Procedural. Spanish. Recepción original: 06/07/2012

Aceptación original: 13/07/2012

Sumario: PRIMERA PARTE. Introducción. Acotaciones y anotaciones a la obra del Dr. D. Manuel Jesús Cachón Cadenas «Historia de Procesalistas, Universidades y una Guerra Civil. (1900-1950)».

SEGUNDA PARTE. Intento de construcción de la parte general de la Historia de la Ciencia Jurídica Procesal Española; I. Precedentes y precursores. La fuente material directa; II. Naturaleza de la Ciencia Histórica Procesal Española. Autonomía y Dependencia; III. Fundamento; IV. Terminología. Aproximación al concepto; V. Método; VI. Partes de la disciplina; VII. Elementos esenciales. Especial atención al objeto y al sujeto; VIII. Elementos accidentales; IX. La historia española de otras ciencias jurídicas. Derecho comparado. Italia y Franco Cipriani. Hispanoamérica; Bibliografía

PRIMERA PARTE. INTRODUCCIÓN. ACOTACIONES Y ANOTACIONES A LA OBRA DEL DR. D. MANUEL JESÚS CACHÓN CADENAS «HISTORIA DE PROCESALISTAS, UNIVERSIDADES Y UNA GUERRA CIVIL (1900-1950)»

El profesor Dr. D. Manuel Jesús Cachón Cadenas, Catedrático de Derecho Procesal de la Universidad Autónoma de Barcelona acaba de publicar este año 2012, en Agosto, un libro que constituye la obra descrita en el título que antecede y que contiene ni más ni menos que 684 páginas y ha sido editada en Madrid por la Universidad Carlos III y la Editorial Dykinson S.L.

Esta obra recoge el contenido de varios artículos (14 en total) que serían una manifestación de lo que nosotros denominaríamos la parte especial de la ciencia histórica jurídica procesal española y que el autor, repito de nuevo -y no podemos ni debemos olvidarlo en ningún momento-, denomina con el título antes referenciado por las razones que considera convenientes y que destaca en sus primeras páginas.

Dichos artículos, como destaca su autor, unos fueron publicados anteriormente en revistas especializadas de derecho procesal sobre todo en la revista Justicia; otros fueron insertados en estudios en 
homenaje a procesalistas españoles con motivo de su jubilación (a salvo del artículo en homenaje al profesor italiano de derecho procesal Franco Cipriani); y finalmente otros van a ser objeto de reciente aparición en revistas de derecho procesal, o en un estudio homenaje a otro (en este caso a otra) procesalista y algunos están en espera del destino apropiado que quiera darles su autor.

Por tanto unos ya aparecieron antes y se recopilan en este libro; otros ven la luz por primera vez en este libro pero serán objeto de ulterior publicación en revistas o en un libro homenaje y finalmente otros podrán ser objeto de ulterior publicación siempre que el autor lo considere conveniente.

Se trata de unos estudios que guardan una concatenación entre sí y justifican que formen parte de lo que el autor como tal titula en la obra que los recopila y que para nosotros formarían la parte especial de lo que denominaríamos y por ello denominamos historia de la ciencia jurídica procesal española; por tanto tendrían autonomía propia en una construcción doctrinal en cuanto diferenciada de la construcción que se hace por los estudiosos de la historia del derecho o por así decirlo de forma más concreta y precisa por los historiadores de esta disciplina aunque esta materia a la que denominamos familiarmente y quizá con un cierto atrevimiento anticipado «nuestra historia de la ciencia procesal española» sea totalmente dependiente del derecho procesal.

Estos estudios como menciona el autor y acabamos de destacar se publicaron en diferentes momentos más o menos espaciados temporalmente. Esto supone que el autor ha dedicado a ellos gran parte de su labor investigadora desde que obtuvo su cátedra de derecho procesal hace casi dos décadas; por tanto suponen varias horas de esfuerzo diario, durante varios años de su vida; es decir, una parte de su vida plenamente dedicada, total o parcialmente, a la investigación de la historia del derecho procesal español.

Siempre entendida dicha historia procesal en sentido estricto por tanto desde que se desgaja el derecho procesal de sus antecedentes remotos, es decir, de los estudios que le dedicaron «los prácticos» y que nos dejaron en sus susodichas "prácticas forenses»; y se desgaja de sus antecedentes próximos es decir de los estudios que le dedicaron «los procedimentalistas» en sus "procedimientos judiciales» y se pasa a estudiar e investigar con carácter científico a través del método propio y específico que como disciplina autónoma exige. 
Se añade que algunos de estos artículos han sido objeto de un «estímulo público especial y oficial», merced a la ayuda que el Ministerio entonces competente otorgó a varios Departamentos de Universidades Públicas Españolas entre las que se incluye la del autor, para una investigación histórico jurídica que forma parte de un I+D.

El objeto de estos estudios es múltiple. Para ilustrar al lector que todavía no conozca la obra -y sin perjuicio de las lógicas y adecuadas precisiones que el autor hace en el prefacio- procedemos a enumerarlos por el respectivo orden en que se insertan:

1. Cátedras y Catedráticos de Procedimientos Judiciales y de Derecho Procesal durante la primera mitad del S. XX.

2. Una reseña tardía con algunos episodios tempranos. (Franco Cipriani).

3. Las oposiciones a la Cátedra de Derecho Procesal de la Universidad de Zaragoza celebradas en 1932; mito y realidad. (Leonardo Prieto-Castro, Niceto Alcalá-Zamora)

4. A propósito de la publicación del libro «Derecho y Proceso» de Gómez Orbaneja.

5. Apuntes sobre la vida y la obra de un insigne procesalista catalán. José Xirau Palau.

6. El expediente de responsabilidades políticas iniciado en 1940 contra el profesor Emilio Gómez Orbaneja.

7. Desventuras de José Casais Santaló, primer traductor español de Chiovenda.

8. Un procesalista español truncado por la Guerra Civil: Agustín Iscar Alonso.

9. Las oposiciones a la Cátedra de Derecho Procesal de la Universidad de Santiago de Compostela en 1932. Ingreso de Niceto Alcalá-Zamora y Castillo en el profesorado universitario.

10. Pugna tenaz por la cátedra de Derecho Procesal de la Universidad de Valladolid con una Guerra Civil en medio (y otras historias poco loables).

11. Adjudicación de la Cátedra de Derecho Procesal de la Universidad de Madrid a Jaime Guasp: datos complementarios casi setenta años después.

12. Noticias sobre una traducción inédita de la obra maestra de Fiedrich Stein. 
13. La difusión en forma manuscrita, litografiada y tipografiada de las explicaciones de clase de Francisco Beceña: dudas, certezas y algunos hallazgos.

14. Cátedras y Catedráticos de Procedimientos Judiciales y Práctica Forense en la primera década del Siglo XX. obra.

La obra finaliza con un copioso índice común y general a toda la

Llegados a este punto y con respecto a esta Primera parte deseo destacar que nuestro objetivo en ningún caso busca prologar esta obra. El autor es un Catedrático de Derecho Procesal sobradamente conocido y de gran prestigio en España como en el extranjero y un prólogo siempre tiene como objetivo presentar formalmente a un autor desconocido como su obra -igualmente desconocida- dentro de un círculo social, de trabajo o de investigación. Se añade que un prólogo acompaña a la obra que la contiene en sus páginas iniciales.

Además sería un «atrevimiento» por mi parte cuando ni siquiera ostento la condición de catedrático intentar semejante «desmesura» de prologar una obra de esta envergadura e importancia.

Tampoco puede considerarse mi labor como una recensión en sentido estricto respecto a los trabajos recopilados en esta obra que vieron la luz hace ya muchos años. La recensión busca destacar los aspectos más importantes y novedosos de un trabajo científico que acaba de aparecer, sin perjuicio de la adecuada crítica constructiva. El paso del tiempo hace que lo novedoso pierda ese carácter y aunque siga siendo su contenido muy importante, incluso tanto, como cuando salió a la luz por primera vez su referencia sería hoy extemporánea.

En este sentido una recensión solo podría tener sentido respecto a los trabajos que en esta recopilación ven la luz por primera vez pues respecto a los aparecidos hace ya algún tiempo, como señalamos, sería extemporánea y por ello estaría fuera de lugar.

Sin embargo, en sentido amplio y por la importancia del conjunto de la obra que podría justificar el nacimiento «a mi modesto entender» de una nueva ciencia histórica procesal española puede tener sentido y repito valiendo de nuevo «la redundancia» en sentido amplio hacer una recensión "global o del todo» que trato de llevar a cabo. Pero siempre una recensión desde un plano abstracto, que no concreto, a fin de cumplir el objetivo trazado y partiendo de que todos estos artículos forman un conjunto sistemático, encadenado, ordenado y destinado a un fin. Pero como recensiones de esta clase a 
artículos muy espaciados temporalmente y diferentes, en abstracto y de forma global no son propiamente «tales» por todas las especificaciones señaladas en líneas anteriores preferimos titular este epígrafe que forma la primera parte de nuestro trabajo como acotaciones y anotaciones a la obra citada del Dr. Cachón Cadenas.

Todos estos estudios, con la amplitud y profundidad que dedica el autor a cada uno, creo que es la primera vez que aparecen recopilados y recogidos en una obra de carácter procesal en España.

Es importante destacarlo porque existen algunos estudios anteriores biográficos y bibliográficos profundos, aunque sean pocos, debiendo destacarse los realizados uno por un procesalista como es el profesor Montero Aroca y otro el realizado por un historiador del derecho que es el profesor Bermejo Castillo ambos dedicados al procesalista Francisco Beceña González (el primer trabajo que conozco dedicado a este autor, muy breve, significativamente, es del mercantilista Menéndez Menéndez y posiblemente sea a Beceña a quien mayor número de trabajos se le han dedicado); existían también otros trabajos breves -hasta la obra de Cachón Cadenas-dedicados a otros procesalistas. Eso sin contar las citas a pie de página en monografías y artículos doctrinales que son las más en número y con meras referencias, en ocasiones más o menos extensas, a las obras e incluso a aspectos de la vida de los procesalistas que se iniciaron al comienzo de la andadura de la disciplina derecho procesal.

Pero que sepamos esa labor investigadora iniciada de forma fecunda sobre esta ciencia histórica procesal española no se continuó por otros procesalistas españoles hasta que aparece por fascículos la obra del profesor Cachón Cadenas ahora recopilada en este libro. Basta mirar el índice bibliográfico del profesor Cachón Cadenas en esta obra, totalmente actualizado, para comprobar que esta afirmación nuestra quizá «no sea del todo equivocada».

Es cierto que existían recensiones hechas en su día a las obras de los primeros procesalistas españoles; existen notas de bienvenida y felicitación de la época a dichos procesalistas por la obtención de sus Cátedras; existen "laudatios» universitarias; hay notas necrológicas recordando tristes nuevas; existen comentarios más o menos afortunados sobre sus particulares obras u otros aspectos en infinidad de citas bibliográficas que, como decíamos, son las más; tampoco se puede olvidar la labor de los diccionarios jurídicos biográficos y bibliográficos de los que en la actualidad conozco tres y que han supuesto y van a suponer, en cuanto todavía no está alguno concluido, a través de sus "voces» un notable impulso; existen resúmenes de 
la vida y obra académica de procesalistas que se insertan como un estudio inicial más añadido a los estudios en su homenaje; a ello se suman los archivos documentales de las Universidades Españolas, de la Junta de Ampliación y de su sucesor Consejo de Investigaciones Científicas tras ser disuelta aquélla en 1939; los archivos documentales del Ministerio competente respectivo (no lo definimos con el nombre actual ya que cambió su denominación en atención a los diferentes momentos que configuran las etapas de su historia) e incluso notas de periódicos sobre todo locales que recuerdan acontecimientos relacionados con nuestro derecho procesal en mayor o menor medida.

Respecto a procesalistas anteriores a 1950 debe destacarse que unos fueron objeto de estudios históricos. Otros a la vez primero fueron sujetos que confeccionaron esta labor y luego fueron objeto de estudio como Alcalá-Zamora y otros de momento son personas que se han ocupado de esta labor investigadora histórica y en el futuro pasaran a ser personas que serán objeto de su estudio. En suma, como la vida misma.

En ocasiones, repito de nuevo, coincide en la misma persona el sujeto objeto del estudio histórico y el sujeto que investiga a otro desde el plano historicista procesal como referimos en el anterior párrafo. En otros como los mencionados Cachón y Montero Aroca se han ocupado de analizar personajes históricos de entre los que conocemos.

Refiriéndome a estos personajes, casi todos catedráticos de la disciplina, que fueron objeto de estudios históricos desde el plano procesal (y rogando el perdón anticipado del lector ya que siempre es posible que silencie a varios autores por un mero lapsus del que me hago totalmente responsable como igualmente por mi propia ignorancia, que afortunadamente es mucha y de la que me siento muy reconfortado... ya que como siempre van a quedar lagunas y omisiones muy a mi pesar....) y tratando de seguir un orden más o menos cronológico de los que eran catedráticos de la disciplina hasta el año 1950, repito de nuevo refiriéndome a los que fueron objeto de estudios o referencias biográficas o bibliográficas de este tipo merecen ser citados Montejo Rica, Fábrega y Cortés, Miguel Traviesas, Álvarez y González-Posada (Melquíades), Marcos Pelayo, Xirau Palau, Beceña González, De Miguel Romero, de Pina Millán (en Méjico), Serrano Suárez, Gómez Orbaneja, Prieto-Castro y Ferrándiz, AlcaláZamora y Castillo, Sentís Melendo (aunque no era catedrático si no Magistrado siempre se le citó con éstos por la profundidad con que 
se ocupó del derecho procesal y de los procesalistas desde el exilio), Guasp Delgado, Silva Melero, Enciso Calvo, Gutiérrez-Alviz Armario, Martínez Bernal, Gordillo García, Fairén Guillen, De Miguel Alonso y Herce Quemada, ... y otros muchos más aunque de época anterior que en breve aparecerán en las voces de estos diccionarios biográficos y bibliográficos que se van insertando, muy especialmente las voces que posiblemente este mismo año vean la luz en el diccionario que se está llevando a cabo bajo el patrocinio de la Universidad Carlos III y otras Universidades consecuencia del I+D al que ya hicimos alusión.

También como personas que se preocuparon de que la obra de Chiovenda tuviera significación inicial en España debe destacarse a Gallardo González y sobre todo a Casais Santaló primer traductor de su obra «Principios de Derecho Procesal».

Pero repito una obra de esta envergadura y entidad con todo el esfuerzo que ha supuesto para el profesor Cachón en España se desconocía hasta la fecha.

Si observamos los 14 trabajos que la componen inmediatamente nos daremos cuenta la importancia que da el autor al aspecto biográfico y bibliográfico, como no podía ser menos, del procesalista español (con la excepción del trabajo segundo dedicado a Franco Cipriani que aunque sigue la misma línea se refiere a la historia del derecho procesal italiano). A ello se une, igualmente, la importancia que dedica a la Universidad y en especial -como nexo indisoluble- la importancia que tiene para él y que da a la Cátedra de Derecho Procesal y a la oposición a ésta en cuanto medio de acceder a ella.

La Universidad y la Cátedra de derecho procesal y los sujetos que la detectan se configuran como el elemento necesario y diríamos casi indisoluble del quehacer científico e investigador en esta obra, sin perjuicio de que realmente lo fuera o no en su inicio y en toda su medida (años 1910-1920). Incluso cuando se refiere a profesores que no llegaron por distintos motivos a la Cátedra lo hace desde esa perspectiva siempre pensando en su acceso a ella.

Siempre sin perjuicio de que en el futuro se pueda decantar si así se estimara conveniente por personas que, tal vez, no ostentaran esa condición de catedrático ni sean de la Universidad; o se decante por trabajos más «objetivados» referidos a determinadas leyes procesales de esa época o incluso anteriores y su significación; o el cambio de su interpretación procesal por la labor de otros Tribunales o del Alto Tribunal durante ese periodo. 
Otro elemento, igualmente de suma importancia para el autor, como denomina en el propio título es la Guerra Civil y su influjo para nuestra disciplina (aunque espero y deseo, a título exclusivamente personal, que con el paso del tiempo se deslice por sus cauces este elemento circunstancial más o menos accesorio sin perjuicio de que pueda ser un elemento estabilizador o desestabilizador para quien escriba sobre ello reabrir «la memoria histórica» o quizá hablando con mayor propiedad reabrir un episodio de nuestra historia cada vez más lejano afortunadamente, pero muy triste, como fue la contienda, para recordarlo y aprender de los errores que llevaron a la misma).

Repito de nuevo, en efecto, como se señala en el título es muy importante para el autor la guerra civil y entiendo que para el derecho procesal también lo fue por las consecuencias inmediatas posteriores que produjo en nuestra disciplina y que no estaría mal que fueran objeto de investigación hasta sus últimas consecuencias.

Sin embargo me impresiona la gran objetividad y mesura con que trata el Dr. Cachón Cadenas esa cuestión y este particular lo cual no siempre es fácil; aunque demuestra que para él sí lo es al estar apoyadas sus afirmaciones en un inmenso fondo documental de archivos oficiales públicos que maneja y conoce con suma perfección y por supuesto los expone con singular maestría.

Como luego destacaré dentro del objeto de esta Ciencia histórico procesal pueden estar aspectos biográficos, bibliográficos así como otros que los apoyan como la Universidad y la Cátedra o que los modifican como en este caso, accidentalmente, la Guerra civil. También otros, a título de mero ejemplo el papel de los Jueces y la Magistratura con el Derecho Procesal, o los Abogados, Ministerio Fiscal y Abogacía del Estado respecto a las reformas procesales en este periodo histórico. Sin olvidar a las leyes procesales estudiadas de forma autónoma, fuera por tanto de la obra de dichos autores procesalistas del periodo.

Entiendo que esta obra, en su conjunto, para cualquier procesalista que hace de su profesión su «oficio» («y no su beneficio»), es fundamental.

Me causó sorpresa, pues no lo esperaba de un procesalista como es el profesor Cachón Cadenas, (aunque sí se espera de un historiador del derecho) la precisión con que utiliza el método empírico de investigación aplicado a las ciencias históricas. Él lo explica muy bien sobre todo cuando agradece en este aspecto los consejos, las 
observaciones, las advertencias, en suma la ayuda prestada por el profesor Carlos Petit destacado especialista e investigador de la Historia del Derecho. En efecto, yo qué en su día quise hacer «pinitos en la materia y no acerté en la medida que pretendí» soy consciente que dicho método ofrece muchas ventajas al investigador y el profesor Cachón lo sabe bien cuando lo aplica y se sirve de él; tanto al manejar los archivos documentales como cuando utiliza el método histórico comparado unido con la experiencia social de la ciencia histórica.

Pero además el profesor Cachón como buen jurista que es utiliza el método técnico jurídico de investigación aplicado a las ciencias del derecho positivo, en nuestro caso al derecho procesal. Con lo que esta combinación se hace perfecta en la obra al perfeccionar el objeto de la investigación.

Esto es muy importante pues no se trata de restar valor al trabajo de los historiadores del derecho sin perjuicio de que sean licenciados en derecho los que lo son o no lo sean los que lo son en geografía e historia. El método empírico aplicado a las ciencias históricas da los frutos que se pretenden y son su objetivo. Y es el método aplicado convenientemente para la Historia del Derecho.

Este método unido a conocimientos de paleografía (escritura antigua) y lenguas más o menos muertas (latín; o el castellano, gallego, catalán ...en sus modalidades antiguas o romance) son muy provechosos sobre todo para investigaciones de la Edad Moderna, Media y Antigua.

Sin embargo para una investigación histórica tan reciente como la que denominamos Historia de la Ciencia Jurídica Procesal Española sin perjuicio de los frutos que puede dar este método histórico (inferiores que para los otros periodos históricos referenciados en el anterior párrafo) y de la ilusión e interés que pueden mostrar los estudiosos de la historia del derecho por este periodo histórico procesal es necesario añadirle el método jurídico aplicado a las ciencias del derecho positivo para extraer todos los frutos.

Pero que no se nos malinterprete: aquí no se trata de excluir a nadie y mucho menos a los historiadores del derecho cuyo fin investigador es el mismo que el de todos cual es la obtención de los máximos resultados pretendidos; sólo exhortarles, en la medida de lo posible y siempre que no les suponga un excesivo trabajo añadido, a un previo estudio del derecho procesal vigente español respecto a la institución histórica procesal que pretendan investigar de este periodo 1915-1950. Y que a una investigación tan reciente de una 
ciencia como la mencionada que prácticamente surge en 1915 apliquen junto al método empírico aplicado a las ciencias históricas el método técnico jurídico aplicado a las ciencias del derecho positivo y los frutos se verán acrecentados en la misma medida.

Creo que en esta medida reside el acierto del profesor Cachón, en esta obra, al utilizar ambos métodos en esta investigación. Y lo hace, entiendo, con una gran modestia que roza la máxima humildad, hasta el punto de que en ocasiones parece imperceptible cuando está utilizando uno de estos dos métodos y cuando el otro. La simbiosis es perfecta.

También entiendo que esta obra puede ser un acicate para impulsar la investigación en una materia inexplorada o muy poco explorada todavía. Se trata de una "selva todavía virgen»; estamos ante una parte especial incipiente de una disciplina cuya parte general parece que está todavía por nacer pero en la que se están depositando las semillas que la harán germinar.

Ayuda también enormemente la lectura de la obra la prosa empleada por el autor que consideramos sencilla y amena para el lector incluso cuando se abordan temas complejos, difíciles, espinosos. Pueden al lector pasársele las horas sin darse cuenta del tiempo trascurrido leyendo el texto.

Es como decíamos, también, un texto comedido, equilibrado, mesurado, proporcionado cuando trata de temas espinosos como la política, la guerra civil o el resultado de algunas oposiciones a Cátedra. Lo hace sin alarde, sin un pretendido posicionamiento lo cual no es sencillo en especial cuando somos de carácter latino y por ello nuestro posicionamiento suele ser más acentuado y apasionado.

Que la prosa es sencilla y amena no implica que deje de ser rigurosa. Lo es y en gran medida por los dos métodos empleados llevados a sus últimas consecuencias.

No abundan las afirmaciones gratuitas y cuando se hacen afirmaciones más que tales son conclusiones sobre una base documental objetiva extremadamente sólida que nos demuestran su certeza hasta el punto que el convencimiento del autor nos conduce al convencimiento instantáneo. Sólo cuando sus deducciones no pueden ser refrendadas documentalmente las deja en el aire o mejor dicho «en un mar de dudas hipotéticas». (Lo cual además nos confirma la diferencia entre el método inductivo y el deductivo).

La lectura de esta prosa me lleva ineludiblemente a un pasado real no tan lejano que es el de la Universidad y sus profesores; al 
inicio y desarrollo de la carrera universitaria; a las cátedras; a los ejercicios de cátedra y su dificultad dependiendo de las personas que se presentan y los lastres e insatisfacciones que en ocasiones dejan en sus competidores; a las becas de investigación y al papel de la Junta de Ampliación creada en 1907, del Consejo Superior de Investigaciones Científicas y del Ministerio competente; a las primeras tesis leídas por los Colegiales de San Clemente de Bolonia; al mayor o menor adoctrinamiento de la Escuela Libre de Enseñanza fundada en 1876 por Giner de los Ríos F. antecedente de la Junta de Ampliación creada en 1907 y las ideas renovadoras en la enseñanza e investigación; a las ideas regeneracionistas surgidas tras la pérdida de las Colonias en 1898 y su influencia sobre la "Generación del 98» y su influjo posterior en el liberalismo «radical» sobre todo tras la Dictadura y que caló muy especialmente en una muy incipiente y escasa «clase intelectual» universitaria y su cristalización en las ideas republicanas que en 1931 suponen el cambio en la forma de Estado; a la vida del profesorado en la Residencia de Estudiantes surgida en 1910 y que fue suprimida en 1939; al Colegio Mayor César Carlos creado tras la contienda para el profesorado universitario...etc, etc.

Sin embargo para terminar esta parte hay un hecho que poderosamente me llamó la atención del profesor Cachón. Por primera vez hace justicia -y quizá en el futuro esto sirva para que se siga haciendo justicia en ulteriores estudios- al defender expresamente nuestra tradición jurídica histórica procesal heredada de las Partidas en su justa medida y criticar por ello veladamente a Beceña González.

Como bien sabemos fue Beceña González, ese «gran» procesalista, reconocido, prestigioso, reputado, considerado e incluso idolatrado con la mitología constituida en su entorno por todos sus discípulos y seguidores al que consideraban el «mejor de los mejores» de este periodo, el que se encargó (desde su acceso a la cátedra en 1923 hasta su desaparición y posible muerte en 1936 -pues su cuerpo que sepamos nunca apareció y tampoco se sabe a ciencia cierta quienes fueron los responsables de esta desaparición como manifestó su hermana según el trabajo del profesor Montero y sólo existen suposiciones o cábalas de quienes fueron estos-) de silenciar y ocultar dicha tradición.

Su menosprecio (quizá la palabra desprecio sea excesiva) por la tradición procesal española que derivaba directamente de las Partidas aparece claramente manifestada unas veces de forma implícita y otras -las menos- de forma explícita, especialmente, en su obra 
«Magistratura y Justicia»; menosprecio que después inculcó a sus discípulos con mayor o menor éxito para que nos trajeran de Alemania (importación expresa ad hoc) el sistema procesal más autoritario entonces vigente en Europa con la excepción del Ruso - el que tuvo Alemania de 1933 a 1945- en cuanto era la manifestación más palpable de cómo construir un verdadero «Imperio» en el ámbito procesal (véanse los trabajos de Guasp, de Fenech aunque no fuera un discípulo directo de él parece como si lo fuera...y otros autores de principios de los años 40 sobre la posición del Juez al aplicar las leyes vigentes y sobre el carácter «institucional» que se otorga al proceso por Guasp e incluso más tarde el propio Gordillo asumiendo la tesis institucionalista de Guasp) y que fue denunciado este sistema -con la agudeza de que siempre hizo gala- por Alcalá-Zamora y que justificaba en su afirmación de que él nunca había militado en el partido Beceñista así como por Sentis Melendo. (Por supuesto, igualmente, razones personales, aparte....).

Además esta concepción de Beceña implicaba un ataque más o menos directo a la Magistratura, es decir a la posición que deben asumir los Jueces y Magistrados frente a las partes; por tanto no sólo al papel que el juez debe adoptar en la dirección formal del proceso sino incluso llegaba a defender que el Juez asumiera la dirección material del mismo como si de una parte se tratara con el consabido efecto -si se llevara la defensa de esta tesis a su máximo extremo- de la vulneración de las garantías judiciales de la independencia e imparcialidad por el propio Juez.

Aunque también debe decirse claramente que otros discípulos de Beceña no cayeron en esta tentación como Gómez Orbaneja y Prieto Castro que siempre tuvieron muy presente la tradición histórica española.

Cierto que Beceña es un mito y como mito quedará para la historia por su trágica muerte en 1936, por su actividad política en el partido reformista de Melquíades Alvárez y González- Posada en Asturias tierra a la que siempre estuvo vinculado, por los altos cargos públicos que desempeñó (Vocal del Tribunal de Garantías Constitucionales y sobre todo Presidente del Tribunal de Cuentas cargo para el que fue nombrado, aunque no hemos podido corroborarlo, durante el bienio derechista de Alejandro Lerroux a la sazón presidente del Consejo de Ministros; al decir de algunos, aunque no está probado, por un momentáneo desinterés de Beceña por el cargo que se le ofreció de Ministro de Gracia y Justicia y al decir de otros no se le ofreció dicho cargo por temor a la reacción que pudiera 
adoptar una parte de la Magistratura que no veía con buenos ojos su nombramiento como máximo responsable de este Ministerio por su concepción sobre la Magistratura solo en parte plasmada por escrito en su obra «Magistratura y Justicia» lo cual siempre fue destacado por Sentís Melendo desde su exilio y Vicepresidente del Consejo General de Cultura cargo al que renunció en Junio de 1936), amén de su gran fortuna personal heredada de sus antepasados que le convertía en una de las familias más pudientes de la época a lo que alude Montero y que se demuestra en la labor filantrópica de su hermana Camila que desde 1940 se dedicó al desarrollo de la fundación creada en 1952 que lleva el nombre de su hermano.

Se ha comentado, aunque no tengo prueba alguna, de la buena relación de Beceña González y la familia Franco Polo y la familia Serrano Polo aunque reconozco que los sucesos de Asturias tuvieron suficiente entidad para unir vínculos o poner fin a éstos; y que desde 1940 referencias al republicano moderado y reformista Beceña eran bien recibidas sin duda por el relevante papel de algunos de sus discípulos durante la Guerra Civil y postguerra (Guasp, Enciso, Silva Melero, Serrano) frente a las que se referían a Alcalá Zamora, Xirau Palau J.R., De Pina Millán, Bonilla Marín. Todavía hasta hace poco la fundación Francisco Franco reclamaba su memoria, lo que a todas luces resulta extraño, para un político moderado y reformista que seguro no los habría apreciado.

Puedo adelantar que si tuviera que valorar a los tres mejores Catedráticos de Derecho Procesal existentes en 1936, personalmente para mí, no estaría Beceña entre ellos. Sí lo estarían los tres únicos catedráticos que obtuvieron esas cátedras durante la República dos discípulos de Beceña (Gómez Orbaneja en 1931 y Prieto Castro Ferrándiz en 1932) y el tercero que no era discípulo de aquel (AlcaláZamora Castillo también en 1932).

Reconozco que esos dos discípulos, quizá, fueran los mejores hasta 1936 pero me sería imposible decantarme por cualquiera de ellos aunque sea por razones personales pues el primero fue mi profesor de derecho procesal penal en quinto curso de carrera en 1981 y el segundo me prologó en 1989 mi tesis doctoral. Uno destacaba por su excepcional inteligencia y la brillantez de su pluma. El otro era igualmente muy inteligente pero sorprendía por su capacidad de trabajo y constancia. Pero lo dicho es sólo una afirmación meramente personal ya que sobre los gustos no existen, afortunadamente, normas que los regulen. 
Incluso sería discutible si Xirau Palau J.R. debería ser correspondido con el cuarto o debía serlo con el quinto, es decir, por delante o por detrás de Beceña. No se puede olvidar que Xirau era amigo íntimo de Calamandrei con quien tenía una abundante correspondencia epistolar que mantuvo después de su exilio hasta la muerte de Calamandrei; en verdad era el primer admirador español suyo estando muy influido por su pensamiento procesal y por el profundo sentido humanista de la obra procesal de Calamandrei; Calamandrei introdujo a Xirau en el círculo de los procesalistas italianos hacia 1920 y compartía con él una ideología política muy semejante. También estaba muy influido Xirau por las ideas humanistas de su hermano Joaquín que había hecho una tesis luego plasmada en una monografía sobre las ideas filosóficas de Platón y el sentimiento humanista. (Su hermano era catedrático de filosofía y falleció muy joven a los pocos años del inicio de su exilio Mejicano 1946 y estaba considerado como uno de los mejores filósofos españoles de la época y al que estaba muy unido aunque desconozco si militaban ambos en el mismo partido político o en uno diferente). Lamentablemente no encontré o al menos no percibí cuando leí la obra «Magistratura y Justicia» de Beceña aunque pudiera ser superior a la de Xirau manifestación alguna de un sentimiento procesal humanista y afín al garantismo procesal.

Incluso sería discutible en términos comparativos qué puesto podría ofrecérsele al catedrático de Sevilla de Pina Millán. Por supuesto que si tenemos en cuenta sus publicaciones hasta 1936 en España su papel sería muy secundario ya que su Derecho Procesal Civil y su Derecho Procesal Penal como su tesis no parecen ofrecer una entidad sobresaliente. Sin embargo si tenemos en cuenta su obra continuada en el exilio mejicano durante los años 1940-1955, muy especialmente sus estudios de derecho procesal, entiendo que ese papel más bien secundario de su etapa procesal española quedaría muy desdibujado debiendo valorarse esta dimensión en su justa medida y quizá podría llegársele a equiparar con Beceña y Xirau. Cierto que hacer esa dimensión no sería justa pues se hace una valoración en periodos muy diferentes y de haber vivido Beceña veinte años más es muy posible que su papel fuera mucho más sobresaliente que el de Pina Millán.

De todas formas en la parte especial de este trabajo abordaremos la figura del mito en la simbología procesal y el misticismo a que puede conllevar sin perjuicio de que los «gustos» son siempre muy personales y afortunadamente muy diferentes y además no es posible valorar por igual la producción científica de una persona en 
espacios temporales diferentes si entre ellos se produjeron grandes avances y muy relevantes en la investigación, refiriéndome y matizando lo dicho respecto a De Pina Millán.

Parece como si para Beceña fuera una necesidad toda ruptura con la situación doctrinal anterior sustentada en dicha tradición histórica procesal patria (Montejo Rica, Marcos Pelayo, De Miguel Romero, Pina Millán) que ciertamente no era muy consistente científicamente en términos procesales a salvo y con la clara excepción de una obra muy superior a éstas la del gran maestro e historiador del derecho español Ureña y Smenjaud plasmada en su monografía «Obras del Maestro Jacobo de las Leyes» publicada en Madrid en 1924 por Reus sobre todo la parte dedicada a las Flores del Derecho y la dedicada a la Margarita de los Pleitos, a la que Beceña que sepamos nunca se refirió. (Sobre este particular puede verse además el Memorial Histórico Español. Tomo 4 ${ }^{\circ}$ Madrid. ¿1853?)

Aunque se puede afirmar que el sistema procesal de las Partidas no era el más adecuado para el S. XX; sí lo podía haber sido uno que respetara el espíritu de la Ley reguladora del procedimiento al juicio de menor cuantía establecido en la ley de 1838 y sobre todo uno que tomara como base la Instrucción del Marqués de Gerona de 1853 en muchos aspectos antecesora y pionera de la Ordenanza Procesal Austriaca de Klein (si no recuerdo mal de i1896?). Con dicha Instrucción de 1853 se podía haber hecho mucho anticipándonos en más de un siglo a muchas directrices de nuestro actual sistema procesal y sobre la base, en lo que era positivo, de nuestra tradición pero es curioso que Beceña no se refiera a esto en su obra tantas veces citada de "Magistratura y Justicia».

Es cierto que quizá lo mas pernicioso de las Leyes de Enjuiciamiento Civil de 1855 y 1881, heredado del sistema de las Partidas, eran los incidentes y el sistema de impulsión del proceso a instancia de parte (entiendo que incluso más perniciosos que la dominación del principio de escritura heredado también de las Partidas y la excesiva duración y formalismo del juicio de mayor cuantía que por lo elevado de las cuantías para la época desconozco hasta que punto podía congestionar nuestra Justicia) aunque tampoco fueron estos vicios tratados y combatidos por la doctrina del momento.

También es significativo lo poco combativa que fue la doctrina española de la época sobre todo desde 1939 ante la introducción de los múltiples procedimientos especiales que se creaban en cada ley material especial que se dictaba, algunos verdaderamente extravagantes, y que procedían de las Comisiones de Codificación de las que 
formaban parte catedráticos y demás personal de otras disciplinas jurídicas, aunque creo que el lector podrá entender que esa cierta ceguera y sordera de los procesalistas de la época ante esa especialidad, respondía a otros motivos, siempre con las contadas excepciones en que se criticó adecuadamente.

Repito la sinceridad y el valor en este extremo del profesor Cachón en la defensa, en sus justos términos, de nuestra tradición procesal histórica española merece sobradamente ser destacada y reconocida con nuestro elogio. Yo sin embargo soy consciente que quizá haya hecho una defensa excesiva y en demasía de esa tradición de la misma forma que lo hizo Alcalá-Zamora (aún teniendo desde su infancia, por estudiar en el Colegio Alemán, una base germánica, que sin embargo no le hizo sucumbir ante el procesalismo germánico) y porque siempre llevó Alcalá Zamora en su corazón durante su exilio y defendió como catedrático que era de Derecho Procesal esta nuestra tradición histórica procesal patria.

SEGUNDA PARTE. INTENTO DE CONSTRUCCIÓN DE LA PARTE GENERAL DE LA HISTORIA DE LA CIENCIA JURÍDICA PROCESAL ESPAÑOLA

\section{PRECEDENTES Y PRECURSORES. LA FUENTE MATERIAL DIRECTA}

Como señalamos hablar de la historia de la ciencia jurídica procesal española y sobre todo y dentro de ella de su parte general es hablar de algo que ha sido sembrado y todavía no germinó. Lo fue en su parte especial y, como siempre ocurre o suele ocurrir en las demás ciencias jurídicas, ya dio sus primeros frutos. Por ello en breve se espera que algunas semillas de la respectiva parte especial se trasladen a otro espacio más general y germinen creando su parte general. No nació todavía pero en breve, por lo dicho, sabemos que nacerá. Y como nacerá en breve es bueno ir haciendo los preparativos para cuando esto suceda y con este breve y sencillo trabajo, que no tiene otras aspiraciones, me encomiendo a ese fin preparatorio.

El momento inicial determinante de esta Historia de la Ciencia Jurídica Procesal debe ser el del nacimiento como tal del derecho procesal en su dimensión científica en España por tanto desde que se comienza a estudiar con el método científico adecuado, que conocemos, por tanto desde este momento inicial y en este planteamiento histórico inicial 1910-20; el momento final hasta una determinada fe- 
cha que al estar ya concretada por Cachón puede ser perfectamente el año 1950 siempre centrándonos en este momento que es el año 2012.

Esto quiere decir que el momento inicial es fijo y más o menos concreto. El momento final será variable a medida que se sucedan los años.

Por supuesto todo este espacio temporal histórico de nuestra ciencia se podría dividir en varios periodos históricos así: 1) los albores y su recepción 1910-1922 que llegaría hasta que se traduce la obra de Chiovenda por Casais Santaló. 2) Su travesía en el desierto desde 1923 en que obtiene la cátedra Beceña hasta 1930. 3) La época dorada de 1931 a 1936 en que obtienen la cátedra sus tres grandes exponentes y representantes Gómez Orbaneja, Prieto-Castro y Alcalá-Zamora. 4) El intervalo tenebroso de 1936 a 1939 y sus consecuencias. 5) Finalmente su despegue y consolidación con la llegada de los nuevos representantes que sería el periodo de la posguerra 1940-1950.

Precedentes y precursores próximos a esta Ciencia sólo pueden ser los procedimentalistas españoles y estoy de acuerdo con Cachón como algunos de éstos pasan a formar parte directamente de esta historia de la ciencia procesal a medida que van abandonando su planteamiento y método inicial procedimentalista y lo sustituyen por el procesalismo convirtiéndose en procesalistas, sin duda, influenciados por esta nueva corriente que estaba más desarrollada y perfilada en Italia y Alemania. Son éstos quienes propondrán a sus discípulos que se trasladen a dichos países a estudiarlo y en menos ocasiones serán ellos mismos quienes se trasladen con este fin.

Queda fuera, por tanto, de esta historia de la ciencia procesal el estudio del procedimentalismo que sólo sería su antecedente próximo. Por supuesto, igualmente, queda fuera el antecedente remoto de los prácticos y sus obras denominadas Prácticas Forenses.

La fuente material y directa a utilizar es el material normalmente escrito de esa época donde se estudia la disciplina con ese método científico (leyes procesales y su jurisprudencia) de forma general o específica y se hacen referencias mediatas a los autores que lo utilizaron y a sus obras.

Por tanto sus Manuales (empleo la expresión en forma generalizada cuando me refiero a ellos y a lo largo de este trabajo al margen de la denominación que se les dé por el autor ya sea Manual, Tratado, Compendio, Introducción, Fundamentos, Sistema, Curso o se les denomine con la simple expresión de Derecho ...) sobre todo en el primer momento. 
Las Monografías al principio muy escasas (debiendo destacarse la publicidad que en las solapas de estas se hace anunciando futuras monografías de próxima aparición y los catálogos monográficos de las editoriales más importantes de la época que eran la propia Junta de Ampliación de Estudios, la Editorial Revista de Derecho Privado, Victoriano Suárez, Reus, La España Moderna, Bosch, la Biblioteca Jurídica de Autores Españoles y Góngora quizá por este orden en cuanto a la calidad de las publicaciones ... que siempre facilitan en gran medida esta labor). De estas hasta 1920 destacan por su excepcional calidad las de la Junta de Ampliación de Estudios de las que no recuerdo ninguna referida directamente al derecho procesal.

Destacamos así la labor de las editoriales más importantes de esa época que hacían posibles esas monografías.

Artículos doctrinales en las Revistas más importantes de ese periodo entre las que destacan la Revista General de Legislación y Jurisprudencia parte doctrinal fundada en 1853 aunque traía su origen en otras revistas anteriores que vieron su luz desde 1839; la Revista de Derecho Privado creada en 1913 al poco del nacimiento de la Junta de Ampliación de Estudios y de singular relieve; el Anuario de Historia del Derecho Español nacido unos años después; y la revista de Derecho Público que aparece en 1932. Hasta 1936 las revistas son más o menos generales respecto a la temática con la excepción del Anuario de Historia del Derecho Español.

Tras la guerra aparecen las revistas específicas sobre materias determinadas así la Revista de Derecho Procesal en 1945, el Anuario de Derecho Civil 1948, el Anuario de Derecho Penal en la misma fecha, y también por las mismas fechas la Revista de Derecho Mercantil, la Revista de Derecho Notarial, la Revista de Derecho Inmobiliario y Registral y la Revista de Administración Pública. Dentro de las citadas nos referimos a las que más relación, entendemos, tienen con el derecho procesal pero existen otras referidas a otras disciplinas jurídicas que por tener menor incidencia en él no citamos.

Debe destacarse que en el primer momento las revistas tienen carácter general en tanto se insertan artículos de todas las disciplinas. A medida que pasa el tiempo se especializan como ocurre con la de derecho privado y luego con la de derecho público. (Un brillante estudio, sobre esta revista, que merece ser citado es el de Gabriel Guillén) Finalmente desde 1945 se refieren a una determinada disciplina jurídica es decir son especializadas de ésta o monotemáticas. 
En todas estas revistas citadas aparecen artículos de procesalistas o artículos vinculados con el derecho procesal en mayor o menor número.

Igualmente merecen ser citadas las recensiones que aparecen en estas revistas; las notas de bienvenida por el acceso de un procesalista a una cátedra; las laudatio publicadas con motivo de la jubilación de sus catedráticos; o las notas necrológicas anunciando la triste nueva.

También merecen destacarse los Discursos de graduación inicialmente de tesis doctorales que tenían que ser leídas en la Universidad de Madrid (existe una monografía importante que cita Cachón de las tesis leídas en esta Universidad durante el periodo que nos afecta); o discursos en las Universidades españolas pronunciados con ocasión del inicio del curso académico cuando se refieren a temas jurídicos en nuestro caso procesales; aunque también existen discursos diversos con motivo de la solemne apertura de los Tribunales; o Discursos en las Reales Academias con motivo de la investidura de un académico con especial atención a los de las Reales Academias de la Historia, de Legislación y Jurisprudencia, y la de Ciencias Morales y Políticas o monográficos en éstas sobre temas de investigación de sus académicos. También existen discursos monográficos de la Junta de Ampliación pero que sepamos no se refieren al derecho procesal directamente pero sí a la Historia del Derecho aunque mediatamente en ocasiones guardan relación con este.

Asimismo los estudios en homenaje a los catedráticos con motivo de su jubilación (o de su muerte cuando se anticipa a la edad de su jubilación); merecen destacarse también las semblanzas sobre todo en diccionarios jurídicos biográficos y bibliográficos aunque las haya también en las revistas citadas.

También merecen ser destacados los archivos documentales de cada Universidad sobre todo los referidos a su personal docente; los del Ministerio de Educación y Ciencia también objeto de otras denominaciones según cada época en tanto en cuanto sea el competente respectivo; o los archivos de la Junta de Ampliación creada en 1907 y que pudo ver la luz tras muchas vicisitudes previas pues fue autorizada su creación durante un gobierno liberal y se constituyó y mantuvo después por gobiernos conservadores aunque con gran tensión para estos últimos su mantenimiento, incluso, durante la Dictadura de Primo de Rivera y que fue disuelta en 1939 y reconvertida en el Consejo Superior de Investigaciones científicas con sus correspondientes archivos; El fondo documental del Colegio de San 
Clemente de Bolonia y tal vez de la propia Universidad de Bolonia; los archivos de la Residencia de Estudiantes fundada en 1910 por la Junta de Ampliación en cuanto lugar de encuentro de procesalistas y sus actividades en la misma; finalmente las noticias en periódicos públicos como BOE para saber la fecha exacta de convocatoria de oposiciones a cátedra como las de nombramiento de los catedráticos o en los periódicos privados especialmente los locales.... pues éstos también forman parte de archivos documentales. También es muy importante el archivo de la Guerra Civil que antes estaba en Salamanca aunque una parte de sus fondos fue objeto de traslado a otros lugares.

Centrándome en libros, revistas y discursos dicho material se encuentra en diferentes fondos de las distintas localidades y Universidades unos más amplios y otros menos. El fondo de la Biblioteca Nacional es el más importante. Sin olvidar los fondos de la biblioteca de la Universidad Complutense de Madrid y de la Central de Barcelona, Valencia y Sevilla; la del Tribunal Supremo, la del Consejo Superior de Investigaciones Científicas, la del Colegio de Abogados de Madrid (y Barcelona), la del Ateneo de Madrid todos en la capital. Para fondo antiguo para periodos de investigación anterior también destacan los de la Universidad de Salamanca y Valladolid.

Todas estas fuentes materiales se encuentran en unos casos editadas en tanto en cuanto fueron objeto de publicación. Otras en especial los archivos mayoritariamente se encontrarán en textos realizados en máquina de escribir manual aunque pueden existir algunos manuscritos sobre todo en la primera época quizá 1900-20.

La importancia de la máquina de escribir en el siglo XX es notable. Cuando pasé mi tesis a limpio en 1988 se utilizó el ordenador pero todavía se permitía la máquina de escribir eléctrica.

No muchos años antes la máquina manual de escribir era el medio habitual. Todavía recuerdo éstas, en mi niñez, en las oficinas de mi padre de las que era Director Delegado Gerente. Pero mucho antes, mi abuelo Manuel Furelos utilizó, así me lo contaron, las primeras máquinas manuales de escribir existentes cuando como técnico que era en máquinas de vapor de barcos civiles trabajó en Cuba de 1900 a 1902 al servicio del gobierno de los Estados Unidos de América emitiendo informes. Incluso mi abuelo utilizaba la suya propia que era de la primera década del Siglo XX cuando se reincorporó en España a su puesto de técnico en máquinas de vapor de ferrocarriles y mi madre me contaba que en el último curso de Bachiller en 1934 tenía que utilizar para sus trabajos la máquina de 
escribir de su padre y con más frecuencia cuando estudiaba la carrera media y superior 1934-43 en esa ciudad tan entrañable que para mi familia materna era Santiago de Compostela de la que procedían directamente por ambos troncos.

Sirva esto solo de anécdota para ver la importancia que tiene la máquina de escribir en el examen de archivos documentales o de los trabajos de investigación no editados de este periodo. Sin perjuicio de que otros muchos archivos documentales y obras no finalizadas estarán manuscritos y la labor se verá más o menos dificultada dependiendo de la caligrafía.

De todas formas, en relación con lo anterior y para libros sobre todo posteriores a 1940 el sistema de préstamo interfacultativo ayudará en gran medida a encontrar esta fuente directa en ocasiones. Los archivos documentales del Ministerio de Educación y Ciencia, de la Junta de Ampliación hoy Consejo Superior de Investigaciones Científicas, de la Residencia de Estudiantes y el de la Guerra Civil supongo exigirán previa información y autorización para su utilización.

Creo que para comenzar «la andadura» de investigar sobre un tema de nuestra historia de la ciencia procesal española los fondos mencionados pueden ser más que suficientes.

Además el libro del profesor Cachón es -además de novedoso por su amplitud y por el resultado de su ardua investigación- un estímulo y acicate para futuros trabajos de esta naturaleza y dispone al final de un índice bibliográfico de lo más completo para iniciarse.

\section{NATURALEZA DE LA CIENCIA HISTÓRICA PROCESAL ESPAÑOLA. AUTONOMÍA Y DEPENDENCIA}

La historia de la Ciencia Jurídica Procesal Española entendemos que es una ciencia autónoma de la Historia del Derecho. Utiliza como método predominante el aplicado a las ciencias del derecho positivo. Si se utiliza como añadido el método empírico de las ciencias históricas tanto mejor para ampliar los resultados buscados.

No se trata de excluir a nadie y menos a los estudiosos de la historia del derecho. Estos podrán hacer grandes estudios con su método propio sobre todo para épocas pretéritas anteriores al S. XX. Y si se refieren a esta etapa con ambos métodos el empírico propio y el aplicado a las ciencias del derecho positivo bienvenidos sean sus trabajos. En este caso que reclamen la autoría de esos trabajos como 
pertenecientes a la historia del derecho o a la historia de la ciencia jurídica procesal entiendo que sería secundario.

Para un procesalista los estudios referidos a la historia de la ciencia jurídica procesal española siempre tendrán carácter procesal y estarán al servicio de nuestro derecho procesal. Por tanto dependencia del derecho procesal, a cuyo servicio están, sin perjuicio de que formen una parcela especial introductoria de éste que justifica dedicar uno o varios capítulos introductorios dentro de nuestro derecho procesal a esa historia de la ciencia jurídica procesal española.

Para niveles más avanzados podría ser objeto de una asignatura optativa. Justificaría también su investigación, en la medida adecuada, el establecimiento de sus correspondientes cursos monográficos.

\section{FUNDAMENTO}

La historia es maestra de la vida. En este sentido podemos aprender mucho de los que en su día en nuestro país se iniciaron, modularon, configuraron... en suma fueron creando el derecho procesal hasta su configuración actual.

Podemos aprender de sus aciertos, también de sus mayores o menores equivocaciones teniéndolo presente en la plasmación de leyes procesales futuras.

Pero igualmente ello nos ayudará a entender la historia en cuanto evolución, pues la historia es la evolución salvando la redundancia de nuestro derecho procesal que como ciencia social que es no puede desligarse de la sociología y la política.

En efecto detrás de las leyes procesales existe una decisión política que justifica que se hable de un proceso humanista, de un proceso autoritario; de un proceso al servicio de las partes con todas las garantías o de un proceso al servicio del Estado; de un proceso dominado por el máximo exclusivismo jurisdiccional del Estado o de un Estado que considera que el proceso debe ser el último remedio para lograr la tutela judicial. Todo sin perjuicio del proceso como tal y del orden jurisdiccional competente para conocer (civil, penal, contencioso o social) en la jurisdicción ordinaria o del proceso en las jurisdicciones especiales; asimismo para el estudio de los otros medios de tutela jurídica alternativos al proceso para la solución de los conflictos. (Así la jurisdicción voluntaria; el arbitraje; la autocomposición y como instrumento a su servicio la mediación; o la autotutela también denominada autocomposición). 
Además sirve para dar el homenaje merecido recordando y respetando a aquellos que nos antecedieron y tantas horas dedicaron, muchas veces en condiciones extremadamente difíciles y bajo situaciones de penuria económica, para que nos pudiéramos deleitar con su precedente esfuerzo. Cierto que también esto sirve para desmitificar mitos que no debían haberse creado en esa medida y en sentido inverso para que autores desconocidos cuya obra no había sido editada o impresa sean resaltados cuando merced a esta investigación pasa a ser conocida o rescatada.

También nos explicará la incidencia de la Universidad Española sobre todo el de la Universidad Central de Madrid, actual Complutense, que era predominante sobre las demás tanto por los medios económicos, como por los profesores que contaba que solían ser los más sobresalientes al estar sus plazas de catedrático sometidas a concurso de méritos y no al de acceso directo; también porque en ella y solo en ella en un principio se leían las tesis doctorales y se realizaban los ejercicios de cátedra para el resto de las Universidades Españolas sobre todo hasta 1936; y la labor de mecenazgo que ello implicaba. Si bien esto solo nos afectará en tanto en cuanto se refiera al derecho procesal y no a otras disciplinas.

Y también como nacieron las primeras escuelas de derecho procesal sobre todo en esta Universidad se entiendan en sentido estricto en cuanto manifestación de un pensamiento sustentado en unas teorías que comparten sus miembros; o como un grupo de personas que se ponen de acuerdo para sacar catedrático a una persona determinada en detrimento de otros concursantes con independencia del pensamiento jurídico procesal por él sustentado en esas teorías y de la concepción procesal de los miembros que forman el Tribunal. En suma criterios de política científica universitaria o criterios de oportunidad política meramente universitaria a la hora de conceder las cátedras a una u otra persona.

Se une además la labor divulgativa que esta investigación lleva consigo para los estudiosos de otras disciplinas de España y sobre todo en el extranjero para que nos conozcan mejor y en su caso nos aprecien más.

Además entiendo que la dimensión actual de un sistema procesal debe asentarse sobre bases firmes. Las bases que lo sustentan son los pilares de esa evolución histórica y a la vez el resultado de esa consolidación histórica. 


\section{TERMINOLOGÍA. APROXIMACIÓN AL CONCEPTO}

Dos denominaciones, a primera vista, se presentaban adecuadas para designar a esa disciplina incipiente.

Una sería historia del derecho procesal español. La otra historia de la ciencia jurídica procesal española.

En la primera existen cuatro palabras clave: historia, derecho, procesal y español aunque esté integrado el término por cinco. En la segunda estamos ante cinco palabras clave: historia, ciencia, jurídica, procesal y española aunque se componga de siete.

A priori el jurista debe buscar el término adecuado con las menos palabras posibles siempre que estas cubran el mayor ámbito o contenido posible.

Sin embargo salta a la vista inmediatamente que la palabra historia del derecho se corresponde con el significado de una disciplina jurídica autónoma y diferente del derecho procesal. Cierto que los estudiosos de la historia del derecho estudian todas las disciplinas de que se compone el derecho sean las que forman el derecho público o el privado, incluido claro está dentro del derecho público el procesal.

Y lo hacen con referencia a los distintos momentos o etapas desde que existen fuentes formales o materiales es decir sus manifestaciones. (Edad Antigua, Media, Moderna, Contemporánea). Puede ocurrir que una etapa esté sobredimensionada en detrimento de otra; o que se dedique más importancia a aspectos del derecho público (Cortes en la Edad Media; la unión de las dos coronas y su significación respecto a los antiguos Reinos; la Institución de la Monarquía; el Consejo Real; los Validos; la Administración de la Metrópoli y de Ultramar; la significación del Ejercito desde Carlos III; la Hacienda pública y su manifestación tributaria; Iglesia y relación con el Gobierno; el papel de la Inquisición en España; El proceso penal hasta el S. XIX; El Corregidor y los Alcaldes en su significación jurisdiccional; la Diplomacia Española...) en detrimento del derecho privado (régimen de la propiedad territorial y sus manifestaciones, el estado civil de las personas y sus limitaciones; El patrocinio y la encomienda; el comercio terrestre y marítimo y sus instituciones protectoras; el régimen de trabajo bajo los gremios...).

Desde esta perspectiva la palabra historia del derecho procesal no sería la más apropiada para referirnos a la figura a la que nos referimos en este trabajo pues parece claro que los historiadores del derecho (como los procesalistas) pueden estudiar instituciones remotas 
de lo que hoy es «derecho» procesal como en su día lo hicieron los prácticos y los procedimentalistas. Pero el objeto de la práctica y del procedimentalismo pudiendo ser objeto como señalamos de estudio tanto por historiadores del derecho como por los procesalistas quedaría fuera de la Ciencia Jurídica Procesal Española aunque no de la historia del derecho, en este caso, procesal sobre la que trabajarían los historiadores del derecho quizá con mayor intensidad que los procesalistas por serles más próxima aunque también puedan hacerlo éstos aunque les resultará más remota.

Además para el estudio de la Historia del derecho, en este caso del derecho procesal, el método empírico aplicado a las ciencias históricas que utilizan los historiadores del derecho les reportará grandes ventajas ya que suelen estar mucho más familiarizados con él que los procesalistas.

Por esta razón entendemos que es más apropiada la expresión Historia de la Ciencia Jurídica Procesal Española. Cierto que las palabras historia, jurídica en cuanto equivalente a derecho, procesal y española no añaden nada en la determinación por una u otra denominación. Lo esencial sería la palabra ciencia más el término unido de procesal (al entenderse el proceso como una ciencia en el sentido de científico) para referirnos a un periodo que en España aparece hacia 1915 de ahí el sentido de la palabra historia.

Queda fuera la etapa precedente de los prácticos y los procedimentalistas. Sólo éstos en tanto en cuanto abandonan su método exegético expositivo (basado en la excesiva dimensión legal del procedimiento en el sentido de que sólo el procedimiento está en la ley; y expresamente como tal se determina en ella el procedimiento legal que es el que debe ser objeto de estudio) y acogen el método científico positivo correspondiente al estudio del derecho procesal pasarían a formar parte de este periodo.

La expresión ciencia, sinónima de científica y el método para su estudio justifica y permite además la clara autonomía del derecho procesal respecto a otras disciplinas jurídicas y permite la adecuada correlación pero a la vez la adecuada diferencia y separación con las otras disciplinas jurídicas.

De todas formas en este breve trabajo no vamos a justificar la cientificidad y autonomía del derecho procesal pues excede su objeto. Solo señalar que partiendo de la cientificidad del derecho procesal y su autonomía perfectamente delimitada por los autores que la justifican a partir de 1915 los autores españoles que asumen este 
método forman parte del objeto de esta disciplina histórica. De todas formas como el año 1915 quizá no pueda ser determinante si me parece apropiado fijar como momento inicial el año 1900 aunque se refiera más a precedentes con el que empieza el siglo y el momento final podría ser hasta 1950 como concreta el profesor Cachón.

Por supuesto que el momento final se deberá ir ampliando a partir de que trascurren los años y la memoria que se tenga de quienes a ello contribuyeron se vaya serenando. Así pasados 30 años quizá el momento final de este periodo podría ser el año 1980.

Estas son las razones por las que defiendo esta expresión de Historia de la Ciencia Procesal Española. No encontré a simple vista una expresión mejor lo cual no supone que pueda existir.

El español es un idioma muy rico en sinónimos y si alguien encuentra un término mejor y con menos palabras para definirlo no debe existir ningún problema para acuñar esa otra denominación siempre que tenga en cuenta cual es su objeto que no puede ser otro que el estudio histórico del derecho procesal español desde que como tal se estudia con dicho método científico (y que se funda en sus tres pilares esenciales de todos conocidos: la ACCIÓN y derivada de ella la legitimación de las partes; la JURISDICCIÓN contenciosa y su consecuencia de la cosa juzgada; y el PROCESO entendido como el método legal para la solución de un conflicto cuyo objeto debe ser aportado y probado contradictoriamente por las partes hasta la sentencia que lo decide y con la posible impugnación y ejecución de la misma) que justifica su autonomía.

Pero en sentido más amplio se añade no solo la historia del proceso así entendido sino la de los demás medios de tutela jurídica alternativos al proceso como son la jurisdicción voluntaria; el arbitraje; la autocomposición y la posible mediación en cuanto cauce para su consecución; y la autotutela también denominada por otros como autodefensa.

Salvada su terminología el concepto de esta ciencia como señalamos es el mismo que el que se tenga del derecho procesal. Añadiendo esa noción histórica aplicada a ese periodo de 1900-50.

\section{MÉTODO}

Damos por reproducido lo señalado en este trabajo.

El método empírico aplicado para la historia del derecho es decisivo para la investigación de periodos remotos. Mediatamente ayuda 
en cuando se estudia la Historia de la Ciencia Procesal Española y ayudó al profesor Cachón como ya señalé en la parte primera cuando me ocupé de la recensión de la obra de dicho profesor. Pero no es decisivo o el más importante.

Lo decisivo es el método aplicado a las ciencias del derecho positivo y en nuestro caso al derecho procesal aplicándolo sobre la base de la cientificidad y autonomía de la disciplina partiendo de los tres pilares esenciales ya señalados que lo sustentan y justifican. La simbiosis de ambos métodos cuando sea posible será muy positiva.

\section{PARTES DE LA DISCIPLINA}

La parte general se ocupará de los elementos esenciales de la disciplina partiendo de su objeto y ámbito destinado a un fin.

La especial, respetando la general, abordaría personajes específicos sean o no catedráticos aunque mayoritariamente lo sean y sus obras principales, las leyes procesales o la jurisprudencia procesal o los preceptos sobre los que trabajaron; papel del legislador ya como autor mediato o inmediato en el nacimiento de esa ley (si fuera jurisprudencia del TS desde cuando es doctrina legal y cual fue la primera sentencia que la constituyó), papel de las Universidades en el desarrollo de ese derecho procesal histórico relacionándolas con sus catedráticos de derecho procesal; medios con los que se patrocinó el derecho procesal en sus albores; editoriales y revistas en que se plasmaban los libros o artículos más importantes; discursos de graduación o de apertura del curso; los estudios en homenaje a cierto autor; situaciones especiales como la Guerra civil o el papel de los gobiernos conservadores y liberales siempre todo ello relacionado con el derecho procesal. Entiendo por ello que los distintos trabajos del profesor Cachón pueden ser encuadrados en dicha parte especial.

La parte general como luego veremos se puede dividir en varios momentos temporales diferenciados. Albores 1915 a 1923. Despegue 1923 a 1931. Edad de Oro 1931 a 1936 con una guerra que de forma muy triste y traumática la interrumpe y de Consolidación 1940 a 1950.

Desde 1900 con el inicio del siglo a 1915 sólo puede hablarse de precedentes y de remotas noticias científicas que llegan de Italia referidas a sus principales procesalistas Chiovenda, Mortara y Lessona; y de Alemania sobre Köhler, Hellwig, Wetzell, Wach, Kleinfeller y Stein de entre los más sobresalientes (aunque tampoco se puede negar importancia a Planck, Obermeyer, Glaser, Von Kries, Binding, 
Pollak...) o de sus antecesores inmediatos como Münter (primer defensor de la acción abstracta procesal) y O. Von Bülow (primer constructor de los presupuestos y excepciones procesales).

Y también puede dividirse objetivamente por materias. Así la Ciencia histórica procesal civil que fue la primera en cuanto pionera; la penal (apenas tratada por los procesalistas hasta las postrimerías de la guerra y curiosamente por un autor alemán como Goldschmidt en la obra ya citada a salvo que se considere así la de Aguilera de Paz referenciada), administrativa (igualmente apenas tratada aunque si por administrativistas y abogados del Estado), laboral (Casais Santaló), militar y constitucional (se comenzó desde la creación del Tribunal de Garantías Constitucionales en 1932 y merece ser citado Alcalá-Zamora Castillo). Igualmente Ciencia histórica procesal la de los medios de solución de conflictos alternativos al proceso. Sobre todo ello incidiremos después brevemente.

\section{ELEMENTOS ESENCIALES. ESPECIAL ATENCIÓN AL OBJETO Y AL SUJETO}

La historia de la ciencia procesal española solo puede tener como objeto el estudio del derecho procesal español desde que se configura como una ciencia autónoma y con la metodología señalada a su cientificidad dentro de un periodo concreto y determinado que tiene el carácter relevante que le damos en su configuración histórica. (A título de ejemplo 1900-50).

Si el derecho procesal español tiene como objeto el conjunto de normas que estudian nuestra disciplina y con ese método; la historia de esta ciencia procesal vendrá referida igualmente a esas normas y como vieron la luz (aunque entiendo que esto no es lo decisivo) y como fueron estudiadas por los estudiosos en esa época bajo dicho método.

Por tanto la Ley de Enjuiciamiento Civil de 1881 al ser de esta fecha no tiene porqué quedar fuera de esta ciencia. Quedaría fuera en tanto en cuanto fue explicada total o parcialmente antes por los procedimentalistas y bajo un método que no aportara nada (cosa rara) de lo que en esencia se busca por el procesalismo. Pero en tanto que con posterioridad fuera explicada total o parcialmente por procesalistas -sobre todo a partir de 1920- con este método entrarían dentro de esta Ciencia los estudios a ella referidos desde 1920 a 1950. Por supuesto los estudios que sobre la misma sean de fecha posterior a 1950 en principio no formarían parte de la misma sino 
del momento presente del derecho procesal hasta que a medida que pasan los años el momento final fijado en 1950 se amplíe.

Ya sé que esto supone una cierta artificiosidad barroca pero es la consecuencia de que una ciencia histórica para ser tal tiene que tener un momento inicial y sobre todo un momento final o ad quem que determine lo que es historia y lo que sigue siendo presente. En el mundo del derecho no puede ser presente el día de hoy y pasado el de ayer sino que por el contrario la intertemporalidad entre la historia como pasado y el presente exige periodos avanzados.

Lo mismo ocurre con las Partidas. Los estudios iniciales sobre las mismas de los prácticos quedan fuera. Lo mismo los de los procedimentalistas. Entrarían dentro de esta ciencia histórica los realizados de 1920 a 1950 por autores de ese periodo que siguen ese método. Y formarían parte del momento presente los trabajos de fecha posterior a 1950 hechos bajo el método procesal para compararlas con las leyes vigentes, sin perjuicio de la artificiosidad dimensional.

Es conveniente destacar este aspecto. Lo esencial de la ciencia histórica entiendo que son los trabajos científicos elaborados por personas casi siempre catedráticos (aunque esto es accidental y no esencial) con este método sobre las normas procesales españolas y su jurisprudencia en ese periodo de 1920 a 1950. Es lo que justifica por tanto el elemento subjetivo y sus elementos accidentales.

Lo dicho para la Ley de Enjuiciamiento Civil lo es para la de Enjuiciamiento Criminal; la de la jurisdicción Contenciosa Administrativa; o las Leyes reguladora de los Jurados mixtos de trabajo, del Contrato de Trabajo y la Jurisdicción laboral. Igual para las distintas leyes materiales especiales que consagraban especialidades procesales. Igualmente el Código de Justicia Militar y la Ley del Tribunal de Garantías Constitucionales de la República.

Si hablamos de la historia de la ciencia procesal española quedarían fuera las leyes que no fueran españolas si bien en cuanto derecho histórico comparado tendrían el valor consiguiente para ser configuradas en su dimensión histórica como la que tiene el derecho comparado actual respecto a nuestro derecho procesal vigente o «actual». Por ejemplo si cuando se invitó a Xirau a dar conferencias en Italia dió una conferencia sobre el sistema procesal italiano sin referencia alguna al sistema español (cosa muy rara que no suele acontecer) esa conferencia en puridad estrictamente no formaría parte de nuestra ciencia procesal histórica sino de la Italiana aunque 
la incluyéramos dentro de la nuestra en tal caso por razones de oportunidad, bastando con una cita de referencia.

Pero con lo dicho antes entiendo debe hacerse una excepción. Como nuestras leyes de enjuiciamiento tuvieron repercusión en Hispanoamérica y otros países que estaban bajo nuestros dominios si en un determinado país hubiera una norma que fuera igual o muy semejante a la nuestra no debería existir motivo para que si fuera estudiada por un jurista de ese país o del nuestro pudiera formar parte a la vez de ambas Historias de la Ciencia Jurídica procesal es decir de la Española y de la del país en cuestión.

Comprendo que la delimitación, siempre necesaria, no puede hacerse con fórmulas matemáticas porque estamos ante las ciencias sociales. Las cosas no son como los colores blancas y entran en esta ciencia o negras y se excluyen. Hay mucho gris que puede incluirse, y la inclusión o exclusión de las zonas grises con los matices necesarios podría estar justificada en ambos casos.

Lo mismo es reproducible respecto a la legislación específica de las jurisdicciones especiales y de la de los medios alternativos de tutela jurídica al proceso para solucionar los conflictos, como se dijo.

El hecho de que la ley o la jurisprudencia estudiada en ese periodo se hallase vigente o no es irrelevante. Como que en la actualidad siga estándolo o haya sido derogada.

Lo dicho en referencia a nuestras leyes procesales debe ser confirmado en relación a la jurisprudencia de nuestros tribunales sobre aspectos procesales. Caben claro trabajos sobre la jurisprudencia de los mismos en este periodo histórico y puede ayudar mucho para su comparación con la posterior o la más reciente.

Ni que decir tiene que el estudio de la ciencia procesal histórica española se plasma no solo en esas leyes procesales y en esa jurisprudencia procesal sino en las obras de sus estudiosos que lo hicieron en ese periodo histórico y bajo ese método fundándose en ello. Por tanto las recopilaciones legislativas, de jurisprudencia y de esas obras son fuentes materiales y a la vez directas donde se contiene. Dentro de sus obras me refiero a los Manuales, las monografías sobre temas determinados, los artículos doctrinales y discursos de grado o universitarios con motivo de la apertura de un curso o con ocasión de ser nombrados académicos.

Y la crítica a la obra de sus autores es la que justifica que a través de nuestra ciencia histórica mantengamos su mitificación o pasemos a desmitificarlos; o que si hallamos la obra desconocida de uno o 
más autores u olvidada procedamos a darla o darles el valor que se merecen. La labor de Cachón es clara y encomiable.

Entiendo que lo relevante respecto al autor objeto de examen no puede ser nunca su nacionalidad española o extranjera para que entre a formar parte o no de la Ciencia jurídica procesal española. Un autor extranjero que se ocupó del estudio de nuestras leyes y jurisprudencia en sus monografías debe formar parte de nuestra ciencia jurídica procesal española en lo que se refiere a su participación en nuestra historia con su trabajo.

En este sentido creo que James Goldsmidt por su brillantísima obra «Problemas jurídicos y políticos del proceso penal (español). Conferencias». Barcelona 1935 debe ocupar un papel sobresaliente en la historia de nuestra historia de la ciencia procesal penal española ya que su trabajo posiblemente sea el primero en ocuparse de lo que entonces era una de las «cenicientas» del derecho procesal español. (Para otros sería quizá la segunda obra si se considera como tal la de Aguilera de Paz. "Tratado de las cuestiones prejudiciales y previas en el procedimiento penal», Madrid 1904 1. ${ }^{\text {a }}$ edic. y 1917 $2{ }^{a}$ edic. de una calidad científica muy inferior y siguiendo todavía el método procedimentalista pero se observa al redactarla la profunda influencia extranjera como consecuencia de su labor traductora de otras obras jurídicas).

Por el contrario las obras que produjo Golschmidt en Alemania tomando como base la legislación procesal alemana no formarían parte de la historia de nuestra ciencia pero sí de la alemana si en ese país se consideró procedente establecer una ciencia de esta clase.

Entiendo finalmente que también es irrelevante la nacionalidad de la persona que en la actualidad se encargue de destacar y de «rescatar» a personajes españoles de ese periodo y sus obras. Qué un español o un extranjero se encargue o encarguen de destacar y rescatar las obras de ese periodo referidas al derecho procesal español y a sus personajes es irrelevante para que contribuya a formar parte de dicha ciencia, de igual forma que el lugar donde se haga su publicación. Por supuesto entiendo que contribuyen a la misma, en todo caso, aunque no formen parte de la misma al no ser historia sino presente.

Hemos hablado del objeto y como se plasma. De los personajes, mitos que nos legaron obras referidas a ese objeto que era nuestro derecho procesal como quién, en la actualidad, con su obra los 
rescata. Aspectos objetivo y subjetivo que quizás son los más importantes.

Quédanos por tratar el mito y su mistificación. Un autor debe ser valorado por el contenido de su obra. Si es de gran calidad, con justicia debe ser valorada y se justifica su mayor o menor mitificación. A medida que así lo entiende su círculo social próximo se puede producir una «mitificación» del personaje como pasa con los «Dioses en la Mitología». Se le idolatra por los suyos y sus seguidores y se produce un proceso de mistificación.

Pero muchas veces esta mitificación no surge del contenido de su obra. Arranca de factores muy diferentes como la posición preeminente en la política o en puestos públicos de gran prestigio social de un catedrático que de una forma más o menos directa arrastra por su poder político decisiones universitarias. Otras cuando su condición de catedrático es suficiente para controlar o dominar la «Escuela» cuando es única o la «más numerosa» si hay varias, hasta el punto que es él quién decide por su poder universitario el que va a ser catedrático y el que no va a serlo. Finalmente en ocasiones es su poder económico, que no deriva de su posición universitaria, lo que le sirve de instrumento para que se tomen decisiones universitarias de tal calado en su beneficio cuando además de ser catedrático es el director ejecutivo de una de las principales editoriales jurídicas de prestigio o de una revista de igual prestigio hasta el punto de poder decidir quien publica y quién no y a la vez que se publica y que no.

En todos estos casos, como es lógico, el ser humano -en cuanto humano que es- se ve arrastrado por estos condicionamientos y si desea hacer «carrera universitaria» sabe que tendrá muchos puntos ganados a su favor cuando se presente a la cátedra si antes se dedicó a ensalzar, vanagloriar, destacar, resaltar, engrandecer al personaje y su obra; en suma manifestaciones que llevan a la mitificación e idolatrar al personaje y su obra. Esto se multiplica si en vez de una persona lo hacen muchas de su círculo próximo.

Pasados los años la historia de la ciencia puede demostrar lo contrario desmitificando al personaje y su obra poniéndole en el lugar que en su justa medida le corresponde.

Lo mismo en sentido inverso, personajes y autores cuya obra era desconocida o permanecía olvidada son «rescatados» del olvido para ocupar el lugar que en justicia les pertenece. Me parece en este sentido encomiable la obra de Cachón. 
Lamentablemente esto ocurre habitualmente no solo en derecho procesal si no en el resto de las disciplinas jurídicas y demás ciencias sociales.

Creo, sin embargo, que es necesario destacar que la producción científico procesal de este periodo sobre todo de 1915 a 1930 es muy escasa si se compara con la actual.

La razón es obvia. El número de profesores era muy inferior casi aproximadamente diez veces menos que los actuales en nuestra disciplina. El número de Universidades rondaba la docena: Santiago, Oviedo, Salamanca, Valladolid, Zaragoza, Barcelona, Valencia, Murcia, Granada, Sevilla, Madrid, Tenerife y el mismo era el número de sus catedráticos hasta 1936.

El número de estudiantes de derecho por curso era muy reducido. Basta ver su número en las orlas de graduación de derecho de este periodo aunque variaba de unas universidades a otras. El número de revistas era muy escaso siendo casi todas generales a su inicio y solo una específica (Anuario de Historia del Derecho).

Ello tenía alguna ventaja y muchos inconvenientes. La ventaja era que se podía estar al corriente de todo lo que se publicaba a diferencia de hoy, que es imposible. El inconveniente eran las limitaciones de todos los medios existentes para esto.

También los sueldos del profesorado eran escasos (en la Universidad Complutense eran superiores) con lo que el profesorado se dedicaba al ejercicio profesional y los que no lo hacían no podían detraer de su salario cantidad alguna para la investigación.

Es además muy difícil determinar cual debería ser la producción adecuada de un profesor aunque esté dedicado en exclusiva. Es decir, además de la docencia cuantas horas debe dedicar a la investigación y en este caso cual debe ser la calidad de esta.

No es lo mismo la producción del profesor que dedica todos los días cuatro horas a investigar a las que se añaden las dedicadas a la docencia y a la actividad administrativa de la Universidad que el que se dedica a otras actividades. Tampoco es lo mismo un trabajo perfilado hasta sus últimas consecuencias que hace una producción más escasa que un trabajo hecho solo meramente para justificar que se investiga. Un trabajo sobre materias excesivamente difíciles y que exige el manejo de lenguas extranjeras donde domina la producción extranjera que un trabajo sobre materias sencillas y donde se examina solo la producción nacional. 
Hay doctorandos que tardan en defender su tesis menos de tres años y otros que tardan más de diez, sin perjuicio que dediquen el mismo tiempo o diferente. Es cierto que dedicando las mismas horas por día a un trabajo éste será mejor, en principio, cuanto más tiempo se le dedique. A veces es una cuestión de elección publicar poco pero de gran calidad o mucho pero con calidad inferior. Esto además debería ser voluntario y sin patrones determinadores pues entiendo que está muy bien recordar que la Santa Inquisición desapareció con Fernando VII.

Debe destacarse que la producción científica de los trabajos se va a referir sobre todo a la parte general del Proceso para cimentar sus bases y al Proceso Civil. El proceso penal es casi desconocido a salvo de las monografías citadas de Aguilera de Paz que habría sido muy provechosa de haber seguido las línea de O. Von Búlow; y la de Golsdmidt; debe destacarse el impulso dado por Alcalá Zamora a su derecho procesal penal en las lecciones por él redactadas publicado en Reus en 1936 y que tanto le sirvieron para la obra que inmediatamente después de la guerra publicó con Levene en Argentina.

Al proceso laboral Casais Santaló le había dedicado en 1920 Reus una obra muy breve titulada «Estudios de Derecho Procesal. Sobre la jurisdicción del trabajo». (Si miramos la Memoria de la Junta de Ampliación correspondiente al año 1920-21 publicada en 1922 su actividad investigadora es muy amplia si la comparamos con Beceña ambos pensionados por esa fecha y donde se destaca su labor traductora de la obra de Chiovenda y Mattirolo y sobre todo donde se hace referencia a una obra que no conocemos y tampoco si fue publicada sobre la acción penal en Italia y su aplicación a España).

$\mathrm{Al}$ proceso constitucional merecen ser citados dos autores. Alcalá Zamora y Castillo y su obra sobre el «Significado y funciones del Tribunal de Garantías Constitucionales. Conferencia. Madrid $1933 »$; y muy especialmente la excepcional monografía de su padre Alcalá-Zamora Torres en que destaca como constitucionalista «Los defectos de la Constitución de 1931». También existen publicaciones específicas sobre la labor del Tribunal de Garantías Constitucionales.

La jurisdicción contenciosa administrativa no fue abordada en este periodo por procesalistas si no más bien por administrativistas y por abogados del Estado; lo mismo ocurriría con la jurisdicción militar al menos que nosotros conozcamos y por ello en ambos casos no citaremos nombres. 
En cuanto al elemento temporal en la ciencia histórica entiendo que tiene carácter esencial aunque solo sea para añadir o excluir el elemento objetivo o subjetivo. Obras y autores que forman parte de este periodo o quedan fuera. Me remito a lo ya destacado en cuanto al momento inicial y final.

\section{ELEMENTOS ACCIDENTALES}

Existen otros elementos secundarios o accidentales a los que hicimos referencia. Unos son simples medios como la Universidad Española, la Junta de Ampliación de Estudios y el Consejo Superior de Investigaciones Científicas así como el Ministerio respectivo en su labor de patrocinio, la Cátedra y la oposición o el concurso a ésta en cuanto medio de acceso, las Editoriales y las Bibliotecas, la política y la Guerra Civil.

Estos elementos para que formen parte de nuestra historia no pueden estudiarse con carácter general sino indisolublemente unidos al derecho procesal y en tal sentido a ese periodo concreto.

Por ejemplo no basta señalar que la Guerra Civil fue cruenta, atroz.... Si no sus efectos sobre el derecho procesal de esa época en el plano concreto tanto social, legislativo, de los catedráticos que fueron desposeídos de su cátedra se fueran o no al exilio; y sus consecuencias en especial cómo fueron cubiertas las vacantes.

O la labor de encomienda, patrocinio, mecenazgo como en concreto afecta a determinados autores de derecho procesal. O cuales son las bibliotecas que cuentan con el mejor fondo procesal por número de ejemplares; editoriales que más obras de derecho procesal editaron en la época con nombres y títulos; revistas existentes con mayor producción procesal o de mayor calidad con nombres y títulos.

Academias donde se recogen los mejores discursos de ingreso o Universidades donde se leyeron los mejores discursos procesales de apertura de curso o que contaban con los mejores catedráticos; enumeración en la Universidad Complutense de todos los discursos de graduación desde 1900 hasta 1936 en nuestra disciplina con el título y nombre de sus autores a la que ya se ha dedicado una monografía pero para todas las disciplinas jurídicas.

Muchos de estos elementos accidentales son tratados adecuadamente por el profesor Cachón en relación siempre con el derecho procesal de ese periodo. 


\section{LA HISTORIA ESPAÑOLA DE OTRAS CIENCIAS JURÍDICAS. DERECHO COMPARADO. ITALIA Y FRANCO CIPRIANI. HISPANOAMÉRICA}

Hasta el momento presente me referí a la Historia de la Ciencia Procesal Española.

Defendí su autonomía en cuanto a la metodología de la Historia del Derecho.

No sé con respecto a otras disciplinas jurídicas españolas el estado de la cuestión. Sé que el momento de la recepción del derecho comparado y su autonomía científica es muy variable.

Quizá sean los penalistas los primeros en confeccionar un sistema científico penal en el sentido moderno con que es entendido pues sus estudios ya estaban muy avanzados a finales del Siglo XIX merced a la labor de insignes penalistas entre los que podemos citar a Pacheco y Silvela en la segunda mitad del S. XIX; a Groizard, Arenal, Dorado Montero, Cadalso, Bernardo de Quirós y Montes desde el último cuarto del S. XIX a fines de éste; Saldaña, Castejón, Jiménez de Asúa, Cuello Calón, Ruiz Funes y Antón Oneca como los más representativos hasta la segunda década del S. XX. Además muchos de los citados tendrán un papel relevante en la traducción (junto a otros traductores de los que aquí por razones de espacio no puedo ocuparme ni citar) de las obras de la Escuela Italiana y Alemana muy especialmente las aparecidas en la España Moderna. Desconozco si la doctrina moderna ha configurado de forma autónoma una historia de la ciencia penal española y los espacios temporales iniciales y finales así como su utilidad aunque existen muchísimas referencias a la misma desde hace largo tiempo.

En lo civil también los civilistas nos sacan mucha ventaja. Merecen destacarse a García Goyena desde la segunda mitad del S. XIX; a Sánchez Román y a Comas en su último cuarto; y sobre todo a Clemente Diego y Gutiérrez, Atard, Alas García-Argüelles, Ramos Ramos, Navarro de Palencia, De Buen Lozano, Miguel Traviesas (también romanista), Calvo Sotelo J, Castillejo Duarte (también romanista), Valverde Valverde, Dualde Gómez, Infante Pérez, Candil Calvo y a Castán Tobeñas que considero como los más representativos hasta la segunda década del S. XX.

Igualmente en Historia del Derecho merece citarse a Pérez Pujol y sobre todo a Hinojosa a finales del S. XIX y desde comienzos del S. XX hasta la segunda década del S. XX a Altamira, Ureña y Smen- 
jaud, Sánchez Albornoz, Galo Sánchez, Ramos Loscertales todos ellos muy sobresalientes sin olvidar que ya antes de 1920 contaban con la única revista temática específica como era el Anuario de Historia del Derecho Español.

También estaban muy avanzados los estudios de derecho romano por influjo del derecho alemán si bien para el derecho procesal el derecho romano queda más alejado que el derecho civil por lo que no haremos referencia a esta cuestión ni a los autores más significativos de comienzos del siglo XX.

Sin embargo el derecho político y el derecho administrativo que constituían inicialmente una única cátedra no estaban tan avanzados. Merece citarse a González Posada ocupado en la labor investigadora del derecho público desde finales del S. XIX y su máximo representante científico y Royo Vilanova A; también hasta la segunda década del S. XX merecen citarse a Arias de Velasco, de los Ríos Urruti, Fernández Velasco, Gascón y Marín, García Oviedo y Jordana de Pozas.

Lo mismo ocurre con el Derecho Mercantil que hasta la llegada a la Cátedra de Garrigues y Díaz Cañabate a fines de los años 20 no tenía la configuración científica que inmediatamente adquirió con su impronta y posteriormente fue seguida por algún mercantilista coetáneo como, Benito Mampel, Vicente Gella, Langle Rubio (antes penalista), Hernández Borondo y Polo que se unió a su línea investigadora y sobre todo por sus discípulos ya en la época inmediatamente anterior a la Guerra y sobre todo tras esta. civil.

El derecho laboral se configura como disciplina tras la guerra

Me he referido a las disciplinas más relacionadas con la nuestra desconociendo si en éstas se considera o no procedente el establecimiento de una historia jurídica de "su ciencia originaria» desligada y con autonomía de la historia del derecho. De todas formas creo que comparativamente con nuestra disciplina he señalado qué disciplinas estaban más avanzadas a la nuestra o en forma semejante a la nuestra y he señalado a los autores que consideraba más representativos por si fuera procedente un estudio comparativo. Por supuesto si la han configurado o lo hacen será de mucha ayuda para el derecho procesal en términos comparativos.

Esta línea de autonomía de la Historia de la Ciencia procesal se siguió en Italia por Franco Cipriani y examinar su libro puede ser 
de mucha ayuda para su configuración en España. Desconozco su significación en Alemania.

Igualmente sé que en Hispanoamérica existen múltiples estudios de parte especial sobre sus autores más sobresalientes entre los que merece citarse a Couture, Hugo Alsina, Levene, Fix Zamudio. O algunos otros de origen español que desarrollaron su obra en América como consecuencia de su exilio partiendo de las instituciones de dichos países como Malagón Barceló, Alcalá-Zamora y Sentís Melendo. Todo ello está adecuadamente referenciado en la obra de Cachón.

Toda esta labor debidamente estudiada y comparada con nuestra disciplina ayudará mucho a su desarrollo.

\section{BIBLIOGRAFÍA}

A lo largo de este trabajo se han hecho muchas referencias. Sin embargo la del profesor Cachón totalmente actualizada entiendo que sirve de base, acicate y estímulo para iniciarse en esta materia que es todavía una selva virgen por explorar. De su copioso índice bibliográfico y de sus citas a pie de página se extrae material suficiente. Todavía mejor, de sus citas se pueden aprovechar las citas de los autores citados; y con todo lo dicho aprovecho para concluir estas breves líneas que son breves comparadas con la amplitud de la materia que queda por abordar dadas las cuestiones planteadas. 